Port Acadie

Revue interdisciplinaire en études acadiennes

An Interdisciplinary Review in Acadian Studies

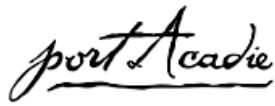

\title{
Les nouvelles frontières culturelles du Québec : le rôle des musées comme marqueurs identitaires
}

\section{Yves Bergeron}

Numéro 13-14-15, printemps-automne 2008, printemps 2009

La résistance des marges : exploration, transfert et revitalisation des traditions populaires des francophonies d'Europe et d'Amérique

URI : https://id.erudit.org/iderudit/038437ar

DOI : https://doi.org/10.7202/038437ar

Aller au sommaire du numéro

Éditeur(s)

Université Sainte-Anne

ISSN

1498-7651 (imprimé)

1916-7334 (numérique)

Découvrir la revue

Citer cet article

Bergeron, Y. (2008). Les nouvelles frontières culturelles du Québec : le rôle des musées comme marqueurs identitaires. Port Acadie, (13-14-15), 321-333.

https://doi.org/10.7202/038437ar

\section{Résumé de l'article}

La mondialisation et la globalisation qui traversent le monde conduisent à une nouvelle configuration des cultures. Autrefois considérée au coeur de ce que certains intellectuels appelaient l'Amérique française, la culture francophone du Québec traverse sa plus grave crise identitaire. Le Québec ne serait-il pas en voie de devenir une nouvelle marge? Après de multiples replis, le territoire culturel du Québec se fragmente et de nouvelles frontières semblent de dessiner. Comment se sont opérés ces changements? Quels sont les mécanismes et les stratégies qui permettent de sortir la culture québécoise de ce processus de marginalisation? Les récents travaux sur le patrimoine au Québec nous donnent des indices de cette crise identitaire et des efforts entrepris pour redéfinir une nouvelle identité collective. Quels sont les nouveaux repères qui balisent le territoire culturel du Québec et qui redéfinissent ces nouvelles frontières? Quel est le rôle de l'ethnologie dans ce processus de résistance et de redéfinition des identités? En somme, cette communication propose une réflexion sur la crise identitaire observée à travers le processus de patrimonialisation de la culture française en Amérique du Nord. 


\title{
Les nouvelles frontières culturelles du Québec : le rôle des musées comme marqueurs identitaires
}

\author{
Yves Bergeron \\ Institut du patrimoine, Université \\ du Québec à Montréal
}

\begin{abstract}
Résumé
La mondialisation et la globalisation qui traversent le monde conduisent à une nouvelle configuration des cultures. Autrefois considérée au cœur de ce que certains intellectuels appelaient l'Amérique française, la culture francophone du Québec traverse sa plus grave crise identitaire. Le Québec ne serait-il pas en voie de devenir une nouvelle marge? Après de multiples replis, le territoire culturel du Québec se fragmente et de nouvelles frontières semblent de dessiner. Comment se sont opérés ces changements? Quels sont les mécanismes et les stratégies qui permettent de sortir la culture québécoise de ce processus de marginalisation? Les récents travaux sur le patrimoine au Québec nous donnent des indices de cette crise identitaire et des efforts entrepris pour redéfinir une nouvelle identité collective. Quels sont les nouveaux repères qui balisent le territoire culturel du Québec et qui redéfinissent ces nouvelles frontières? Quel est le rôle de l'ethnologie dans ce processus de résistance et de redéfinition des identités? En somme, cette communication propose une réflexion sur la crise identitaire observée à travers le processus de patrimonialisation de la culture française en Amérique du Nord.
\end{abstract}

Cette communication repose sur un premier constat qui se dessinait clairement dans l'ouvrage Musées et muséologie, nouvelles frontières ${ }^{1}$ publié à l'automne 2005. Il ne fait aucun doute que la mondialisation qui traverse le monde conduit à une nouvelle configuration des cultures. Nous en sommes tous conscients, mais nous ne mesurons pas toujours les effets directs et indirects de ces changements. On doit cependant retenir que deux grands mouvements résultent de la mondialisation. Le premier concerne la valorisation d'un nouvel ordre culturel. Un peu partout à travers le monde, il semble qu'il y ait adoption de la culture émergente (anglo-saxonne). Dans le même souffle, on observe une remise en question des valeurs culturelles et sociales, de sorte qu'on ne peut plus négliger l'effet des nouvelles générations. On n'a qu'à penser à la montée de la droite et du conservatisme, qui est le fait notamment de la génération X (née entre 1961 et 1981) qui exprime ses valeurs. Il est clair qu'il y a rupture de cette génération avec son aînée et ses parents (babyboomers) ${ }^{2}$.

1. Yves Bergeron (dir.), Musées et muséologie, nouvelles frontières - Essais sur les tendances, Québec, Musée de la civilisation, 2005, 255 p.

2. Voir David K. Foot, Entre le boom et l'écho 2000, Montréal, Boréal, 1999, 387 p. Le 21 janvier 2008, le Journal de Montréal rendait publics les résultats 
Le second changement concerne la résistance des cultures minoritaires et les petites sociétés ${ }^{3}$. C'est notamment le cas du Québec. Dans ce contexte, les cultures dominantes semblent produire un effet de rouleau compresseur sur les autres cultures. Certains auteurs, comme Krysztof Pomian 4 , ont pourtant bien montré que nous n'en sommes pas à la première vague de mondialisation dans l'histoire de l'humanité et que les changements ne surviennent pas toujours là où on les attend. Rappelons simplement le rôle de Rome et la diffusion du latin dans l'Antiquité. Or, malgré le rayonnement de la culture et du latin ${ }^{5}$, on a constaté l'émergence de plusieurs langues européennes qui, bien que partageant des sources communes, se sont rapidement différenciées. Le même phénomène s'observe avec la montée du catholicisme, qui avait aussi pour objectif d'unifier en quelque sorte l'Europe. Et pourtant, cette culture qui se voulait commune a notamment éclaté au xvle siècle avec la Réforme et la contre-réforme.

Plus près de nous, on peut mesurer présentement les effets de la mondialisation au Canada. En même temps qu'on observe cette tendance à l'uniformisation, on note également un mouvement de valorisation des communautés culturelles ${ }^{6}$ et des groupes minoritaires. La politique fédérale du multiculturalisme mise de l'avant par Pierre Elliott Trudeau7 a produit cet effet de valorisation des diverses cultures. On observe les effets du multiculturalisme au niveau des minorités religieuses ${ }^{8}$ qui se multiplient alors que la pratique religieuse diminue chez les deux groupes

d'un sondage Léger Marketing confirmant les hypothèses de Foot : Philippe Pineault, "Les jeunes critiqués», www.canoe.com/infos/quebeccanada/archi ves/2008/01/20080121-053500.

3. Voir Jacques L. Boucher et Joseph-Yvon Thériault (dir.), Petites sociétés et minorités nationales - Enjeux politiques et perspectives comparées, PUQ, 2005, 420 p.

4. Krysztof Pomian, "Les musées d'ethnographie dans l'Europe d'aujourd'hui », Rencontres européennes des musées d'ethnographie, [Paris], Musée national des arts et traditions populaires, École du Louvre, 1996, p. 37-48

5. Le latin restera la langue de la diplomatie en Europe jusqu'au xvII ${ }^{\mathrm{e}}$ siècle.

6. Gisèle Sainte-Marie, Population immigrée recensée au Québec et dans les régions en 2001 : caractéristiques générales, Recensement de 2001 : données ethnoculturelles, ministère des Relations avec les citoyens et l'immigration, mars 2004, 136 p. Cf. www.micc.gouv.qc.ca/publications/fr/recherches-statistiques/ Population-immigree-recensee-Quebec-regions-2001.pdf.

7. Trudeau a fait voter la politique sur le multiculturalisme le 8 octobre 1971 confirmant la volonté de reconnaître le pluriculturalisme comme un des fondements de l'identité canadienne, différenciant ainsi le Canada des États-Unis.

8. Données sur la population recensée en 2001 portant sur la religion. Analyse sommaire, Québec, ministère des Relations avec les citoyens et l'immigration, 27 mai 2003, 10 p. Cf. www.micc.gouv.qc.ca/fr/recherches-statistiques/statsrecensement.html. Dans ce texte, on souligne l'homogénéité religieuse encore dominante au Québec, mais on souligne l'émergence du pluralisme religieux (p. 4). 
jusqu'ici majoritaires, c'est-à-dire les catholiques et les protestants ${ }^{9}$. Plus que jamais le Canada encourage sa politique du multiculturalisme et devient une alternative à l'immigration qui se dirigeait autrefois aux États-Unis ${ }^{10}$.

Mais il y a plus encore. La Convention internationale de l'UnESCO sur la diversité culturelle ${ }^{11}$ et la Convention pour la protection du patrimoine culturel immatérie ${ }^{12}$ indiquent bien la prise de conscience internationale face à la fragilité des cultures. L'UnESCO reconnaît que le patrimoine culturel immatériel " $(P C I)$ - ou patrimoine vivant - est le creuset de la diversité culturelle et sa préservation le garant de la créativité permanente de l'homme ${ }^{13}$.

\section{Aux marges de l'Amérique française}

Voyons maintenant comment se positionne la culture des francophones en Amérique du Nord à la lumière des pressions exercées par la mondialisation.

Le concept d'Amérique française a émergé au xxe siècle sous la plume de certains intellectuels et historiens à l'occasion des grands congrès de la langue française $\left(1912^{14}\right.$, 1937, etc.). Les deux premiers congrès de la langue française ont favorisé une prise de conscience du rayonnement de la culture française en Amérique du Nord et du poids démographique et politique qu'elle représente.

Quand on songe aux acteurs clés qui se sont illustrés pour la défense de la langue et de la culture française, on pense notamment à la

9. Voir à ce sujet Marie-Claude Rocher et Marc Pelchat (dir.), Le patrimoine des minorités religieuses du Québec - Richesse et vulnérabilité, Québec, PUL, 2006, $273 \mathrm{p}$.

10. On peut consulter à ce sujet le site de l'Observatoire statistique d'immigration et métropoles du Centre de recherche interuniversitaire de Montréal sur l'immigration, l'intégration et la dynamique urbaine : http ://osim.inrs-ucs.uquebec.ca/index. htm.

11. Voir Unesco, Convention sur la protection et la promotion de la diversité des expressions culturelles, 20 octobre 2005 (http ://unesdoc.unesco.org).

12. Voir unesco.org.

13. Voir http ://www.unesco.org/culture/ich/index.php?pg=00002. "La Convention dit que le patrimoine culturel immatériel se manifeste, entre autres, dans les domaines suivants : les traditions et expressions orales, y compris la langue comme vecteur du patrimoine culturel immatériel; les arts du spectacle (comme la musique, la danse et le théatre traditionnels); les pratiques sociales, rituels et événements festifs; les connaissances et pratiques concernant la nature et l'univers; les savoirfaire liés à l'artisanat traditionnel." "

14. Premier Congrès de la langue française au Canada : déclarations et vœux formulés par les sections d'étude, et adoptés par le Congrès en séance générale le 28 et le 29 juin 1912, Québec, Comité permanent du congrès de la langue française au Canada, Université Laval, 1913, 693 p. 
Société Saint-Jean-Baptiste, au Conseil de la vie française en Amérique, à l'historien Lionel Groulx, au mouvement nationaliste canadien-français et à l'Ordre de Jacques-Cartier ${ }^{15}$. Les acteurs et défenseurs de la culture française se sont concertés autour du concept d'Amérique française. À cet égard, il convient de souligner la création en 1946 de l'Institut d'histoire de l'Amérique française par l'abbé Lionel Groulx, qui va regrouper une équipe d'historiens spécialisés dans l'histoire de la culture française en Amérique du Nord. On voit se dessiner dans ce concept l'actualisation du rêve de la Nouvelle-France. Mais il y a surtout dans l'idée d'Amérique française une forme d'appropriation symbolique du territoire nord-américain. Ả ce sujet, l’historien français Pierre Nora, spécialiste de la mémoire, écrit :

L'Amérique française est à la fois une réalité bien vivante,
pourvue d'un dynamisme propre, largement illustrée et
défendue par près de vingt millions de francophones;
et en même temps un pur souvenir, une construction de
l'esprit, une utopie, une vision mythologique, un artefact
historiographique. Un laboratoire et un conservatoire. Une
survivance et un devenir. C'est étrange et c'est passionnant.

Le premier indicateur qui se dessine dans le concept d'Amérique française tient à la langue. Il s'agit bien sûr du dénominateur commun. Les géographes Dean Louder et Eric Waddell ont donné une réponse à la réalité de l'Amérique française en publiant en 1983 un ouvrage intitulé $D u$ continent perdu à l'archipel retrouvé - Le Québec et l'Amérique française ${ }^{17}$. On y voit se dessiner le portrait des francophones au Canada et aux ÉtatsUnis dans la seconde moitié du $x^{e}$ siècle.

Le deuxième indicateur du concept d'Amérique française tient aux traditions des francophones. Les travaux des ethnologues ont montré que l'univers de référence des traditions des francophones en Amérique du Nord est structuré autour du cycle agraire et du cycle calendaire de l’Église catholique. Nous sommes là dans l'univers culturel du catholicisme. On n'a qu'à penser aux recherches et publications de Marius Barbeau et notamment de Luc Lacourcière et des Archives de folklore de l'Université Laval $^{18}$. Cette association entre langue et religion catholique est si étroite

15. Voir G.-Raymond Laliberté, Une société secrète : l'Ordre de Jacques Cartier, Montréal, Éd. Hurtubise HMH, «L'homme dans la société », 1983, 395 p.

16. Pierre Nora, «Préface », dans Yves Bergeron et Alain Beaulieu, Amérique française l'aventure, Montréal, Fides, 2002, p. 7.

17. Dean Louder et Eric Waddell (dir.), Du continent perdu à l'archipel retrouvé - Le Québec et l'Amérique française, Québec, Presses de l'Université Laval, 1983, 289 p.

18. Voir Anne-Marie Desdouits et Laurier Turgeon (dir.), Ethnologies des francophones de l'Amérique et d'ailleurs, Québec, PUL, 1997, 351 p. 
que les travaux des ethnologues ont négligé l'étude des francophones protestants ${ }^{19}$, qui ont choisi de s'installer plutôt aux États-Unis.

\section{7 : l'année de l'exposition universelle et des grandes ruptures}

Il convient notamment de souligner les États généraux du Canada français en 1967 à Montréal $^{20}$, qui marquent un moment clé dans l'affirmation de la culture française en Amérique du Nord. On constate alors la perte de terrain de la langue française au Canada. Plusieurs chercheurs constatent l'érosion des traditions et les transformations des pratiques culturelles dans la vie laïque. La rupture des Québécois avec les autres communautés francophones du Canada à l'occasion des États généraux met fin en quelque sorte à un nationalisme canadien-français d'un océan à l'autre. L'affirmation d'une identité québécoise provoque alors l'éclatement de la coalition canadienne-française. C'est l'époque de l'affirmation nationale et une chanson populaire marque ce tournant : «Nous sommes Québécois » ${ }^{21}$.

\section{Vague de changements}

Les années 1990 marquent également une période de changements profonds. La mondialisation ouvre la voie à l'« autoroute de l'information ", qui va bousculer les modes de communication. On entre alors dans l'économie du savoir. Du même coup, on voit disparaître les grandes structures industrielles qui avaient permis le développement de l'économie et de la société canadienne. Les industries du textile ferment les unes après les autres, les usines de pâte et papier entrent dans la concurrence internationale et sont absorbées par de grands conglomérats internationaux avant de fermer leurs portes, car on considère que les usines ne sont plus assez productives et compétitives.

Le Québec est notamment marqué au même moment par un second référendum qui secoue le Canada tout entier. Sans l'intervention illégale du Canada, le « oui » aurait probablement remporté le référendum sur l'indépendance du Québec en 1995, mais les résultats serrés laissent un pays en crise identitaire.

19. À l'exception de la Société d'histoire du protestantisme franco-québécois, rares sont les historiens et ethnologues à se pencher sur cette question. L'historien français, Philippe Joutard, spécialiste du protestantisme a abordé la question dans ses travaux.

20. Les débats se sont étalés de 1966 à 1969.

21. Chanson du groupe québécois les Sinners, qui changent de nom pour s'appeler La Révolution française. 


\section{Le patrimoine religieux comme indicateur de l'identité des Québécois}

Au-delà de l'économie et de la politique, les années 1990 mettent en relief les problèmes fondamentaux que traverse l'Église catholique au Québec. Le taux de pratique religieuse chute à moins de 10 pour cent au Québec. Les églises ne sont plus fréquentées et il n'y a plus suffisamment de prêtres pour desservir les paroisses. De nombreuses fabriques envisagent alors de vendre, de fermer ou même de démolir des églises. II y a plus qu'une crise du patrimoine religieux ${ }^{22}$, il y a crise fondamentale d'un des principaux indicateurs de l'identité des francophones. On constate donc au tournant du $\mathrm{xxl}^{\mathrm{e}}$ siècle que l'univers de référence de la culture francophone se marginalise.

Depuis quelques années, on observe un paradoxe étonnant concernant l'état de la culture au Québec. Alors que les églises et le patrimoine religieux sont menacés de disparition, les musées pour leur part se multiplient. Ils étaient à peine une centaine en 1975. En 2005, on dénombrait 427 institutions muséales sur l'ensemble du territoire québécois ${ }^{23}$. Il semble impensable aujourd'hui qu'un musée ferme ses portes sans que la population et l'État se mobilisent. Qu'est-ce qui explique ce phénomène? Quels sont les liens entre les églises et les musées?

\section{Églises et musées}

Partons du principe que les églises sont considérées par les spécialistes de l'histoire de la muséologie comme les premiers musées ${ }^{24}$. Elles sont à la fois des «lieux historiques» et des «lieux de mémoire ». Depuis toujours, les églises sont des lieux de conservation d'objets mémoriels. On y retrouve des ex-voto, des objets sacrés, des œuvres d'art, de l'orfèvrerie, des sculptures, des tableaux et des sources iconographiques ${ }^{25}$. Mais plus encore, les églises ont joué un

22. Voir les actes du colloque Le patrimoine religieux du Québec : entre le cultuel et le culturel, sous la direction de Laurier Turgeon, Québec, PUL, 2005, 558 p.

23. Voir Yves Bergeron et Suzanne Dumas, avec la collaboration de Geneviève Cardinal et Marie-Thérèse Thibault, État des lieux du patrimoine des institutions muséales et des archives, cahier 3: "Les institutions muséales du Québec, redécouverte d'une réalité complexe », Québec, Observatoire de la culture et des communications du Québec, 2007, 92 p. Cf. www.stat.gouv.qc.ca/observatoire.

24. Krzysztof Pomian, Collectionneurs, amateurs et curieux - Paris-Venise, $x v l^{e}-x V I I^{e}$ siècles, Paris, Gallimard, 1987, 376 p. Dominique Poulot, avec Catherine Ballé et la collaboration de Marie-Annick Mazoyer, Musées en Europe : une mutation inachevée, Paris, La Documentation Française, 2004, 286 p. François Mairesse, Le musée, temple spectaculaire : une histoire du projet muséal, Lyon, Presses universitaires de Lyon, 2002, $215 \mathrm{p}$.

25. Voir Jean Simard, Les arts sacrés au Québec, Montréal, éditions de Mortagne, 1989, 389 p.; et Le patrimoine religieux au Québec - Exposé de la situation et orientations, 
rôle fondamental dans l'histoire des francophones en Amérique du Nord, car elles étaient aussi le lieu de conservation des archives de chaque communauté. On y conservait les registres des naissances, des mariages et des décès. II ne fait aucun doute que les églises demeurent fondamentalement des lieux de valorisation de la culture du sacré et de l'immatériel. Les églises sont devenues des biens patrimoniaux à conserver. Elles font l'objet de débats et d'enjeux de société ${ }^{26}$. En somme, les églises sont fondamentalement des espaces identitaires.

Examinons maintenant les grandes fonctions qui définissent les musées. Bien sûr, il convient de citer ici la définition du conseil international des musées (Iсом), qui précise que le musée est "une institution permanente, sans but lucratif, au service de la société et de son développement, ouverte au public et qui fait des recherches concernant les témoins matériels de l'homme et de son environnement, acquiert ceux-là, les conserve, les communique et notamment les expose à des fins d'études, d'éducation et de délectation ${ }^{27}$. Cependant, la réalité des musées nous apparaît plus complexe aujourd'hui. C'est pourquoi l'Observatoire de la culture et des communications du Québec a précisé cette définition :

Les musées sont des lieux d'éducation et de diffusion de l'art, de l'histoire ou des sciences. On peut les répartir en trois grandes catégories : les musées proprement dits, les centres d'exposition et les lieux d'interprétation.

Les musées ont ceci de particulier qu'ils acquièrent, conservent, étudient et mettent en valeur des collections. Grâce à eux, notre patrimoine est sauvegardé, transmis, offert à tous, dévoilé aux gens de la région comme aux touristes curieux de mieux connaître un coin de pays. Ces institutions effectuent des recherches et réalisent des activités de diffusion : expositions, activités éducatives et culturelles, publications, etc. Un jardin botanique? Un jardin zoologique? Un aquarium? Ce sont aussi des musées car ils possèdent des « collections vivantes » qu'ils rendent accessibles au public. ${ }^{28}$

Québec, Publications du Québec, 1998, 55 p.

26. Lire à ce sujet Luc Noppen et Lucie K. Morisset, Les églises du Québec - Un patrimoine à réinventer, Montréal, les Presses de l'université du Québec, 2005, $389 \mathrm{p}$.

27. Cf. http ://icom.museum/definition_fr.html.

28. Yves Bergeron et Geneviève Cardinal, "Institutions muséales », dans État des lieux du patrimoine des institutions muséales et des archives, cahier 1 : "Premier regard », Québec, Observatoire de la culture et des communications du Québec, 2006, p. 47. 
De manière plus pragmatique, rappelons que les musées sont souvent associés à des lieux historiques, de sorte qu'ils sont souvent considérés comme des lieux de mémoire. Ce sont donc des lieux de conservation d'objets mémoriels (œuvres d'art, objets historiques, objets ethnographiques) et des dépôts d'archives. Tous les auteurs s'entendent pour dire que les musées sont des lieux de valorisation de la culture de l'immatériel. Dans le cas où ils se définissent comme des musées de société, ils deviennent également des lieux de débats.

Depuis quelques années, les musées héritent du patrimoine des fabriques et des communautés religieuses. En ce sens, ils reprennent l'une des fonctions mémorielles des temples. On peut donc dire que les musées contribuent en quelque sorte à la sacralisation de la culture. Bref, les musées se définissent comme des lieux identitaires.

Comme l'a montré Laurier Turgeon dans le cadre du colloque national sur le patrimoine religieux en 2005 , nous sommes donc passés d'un patrimoine cultuel à un patrimoine culturel. Les objets du culte qui faisaient partie de la vie quotidienne des Québécois se retrouvent aujourd'hui dans les musées pour témoigner de pratiques culturelles. C'est pourquoi on peut dire, comme le précisait Jean-Pierre Pichette en introduction à ce colloque, que les musées deviennent en quelque sorte les cimetières de la culture.

Comme autrefois l'Église abritait les œuvres d'art, les représentations du sacré, de l'invisible, les musées jouent aujourd'hui le même rôle au sens laïc. Ils abritent les œuvres majeures produites par la communauté, conservent des collections d'objets mémoriels et les exposent au regard dans un cadre sacré. En somme, les musées prennent le relais des églises et disent qui nous sommes comme société. Il existe donc des fonctions communes entre les églises et les musées.

\section{Recherche de nouveaux indicateurs}

Si la langue, la religion et les traditions pouvaient autrefois définir la culture des francophones en Amérique du Nord, force est de constater que ces indicateurs ont été remplacés. Il semble par ailleurs que les objets patrimoniaux de cette culture trouvent refuge depuis quelques décennies dans les musées. Dans cette perspective, il devient essentiel de mieux cerner les fonctions du musée. La première observation tient au caractère polysémique du concept de musée. En fait, il y a «musée » et «musée ». Comme on a pu le constater, la typologie des institutions muséales est complexe.

La conservation du patrimoine national relève habituellement des musées nationaux, créés par l'État avec la mission bien définie de témoigner de l'histoire et de la culture d'une collectivité nationale. Par 
ailleurs, les musées d'art et d'art contemporain se consacrent en quelque sorte à la recherche de l'exceptionnel (le chef-d'œuvre) et de l'universel. Ces musées sont animés par l'esprit et les valeurs de la mondialisation. Les gouvernements ont tendance à valoriser ce type de musées. Quant aux musées de sciences, ils s'adressent en quelque sorte à la communauté internationale. Ils témoignent de notre contribution au patrimoine de la connaissance universelle. Ces musées s'engagent encore aujourd'hui dans l'esprit des encyclopédistes $d u$ xvIII siècle. On y retrouve une philosophie de l'évolutionnisme et du positivisme. C'est pourquoi les États encouragent également ce type de musées.

Les musées nationaux d'histoire et de société ont pour mandat de conserver et de mettre en valeur les objets qui témoignent de l'histoire et de l'identité nationale. Créés par les gouvernements, ils sont liés aux tendances politiques. De nombreux auteurs qui se sont penchés sur le développement des musées ont démontré que l'histoire des musées est toujours liée aux instances politiques ${ }^{29}$.

Il est éclairant d'examiner plus attentivement le rôle des musées d'histoire et d'ethnologie. Ils semblent de plus en plus problématiques, dans la mesure où ils traitent de questions d'identité. Cette approche des musées de société exige un regard critique et rétrospectif. Ces musées sont devenus au fil des ans des lieux d'expression des identités régionales et collectives. Dans son ouvrage intitulé Des musées en quête d'identité, Serge Chaumier montre les défis que posent les musées identitaires et les musées de société30.

En 2004, on comptait 427 institutions muséales sur l'ensemble du territoire québécois, dont 287 musées d'histoire, d'ethnologie et d'archéologie. C'est donc dire que ces musées constituent plus de la moitié du réseau des institutions muséales. Sachant que l'ensemble du réseau accueille chaque année plus de 12 millions de visiteurs, et que les musées d'histoire et de société en accueillaient en 2004 près de 7700 000, leur fréquentation, qui représente 63 pour cent de la fréquentation totale des musées, n'a donc rien d'un phénomène marginal.

\section{Le Québec entre dans la marge}

De nombreux indicateurs révèlent que la culture québécoise est de plus en plus marginalisée. Autrefois considéré comme le centre (au sens de foyer de l'Amérique française), le Québec devient de plus en plus fragmenté et périphérique. En d'autres termes, le Québec entre dans la marge. Force est de constater que Montréal est en voie de devenir le foyer

29. Voir à ce sujet les travaux de Dominique Poulot et de Kryztof Pomian cités supra.

30. Serge Chaumier, Des musées en quête d'identité - Écomusée versus technomusée, Paris, L'Harmattan, 2003, 272 p. 
d'un nouveau Québec multiculturel, où la langue française n'est plus le dénominateur commun. Les derniers sondages révèlent cette tendance qui se dessine depuis quelques années.

Une chose est certaine, l'anglais progresse comme langue commune dans la grande région de Montréal. Le gouvernement déploie de moins en moins d'efforts pour intégrer les immigrants à la culture francophone. Ce phénomène s'explique en raison des nouvelles générations, qui n'adhèrent plus aux valeurs traditionnelles du nationalisme québécois. Ce mouvement s'exprime notamment dans le déclin du Parti québécois (PQ) et par la remontée de l'Action démocratique du Québec (ADQ) de Mario Dumont.

\section{Les musées comme nouveaux marqueurs de l'identité}

Pendant que les musées se concentrent majoritairement à Montréal et Québec et que les tensions entre Québec et Montréal sont plus fortes que jamais, les musées deviennent des acteurs sociaux de la résistance. Cette observation peut sembler étonnante, mais il faut bien comprendre que la patrimonialisation de la culture populaire indique bien les nouveaux enjeux culturels.

Comme les croix de chemin autrefois, les petits musées (musées de société, maisons historiques, centres d'interprétation, musées de territoire, économusées...) marquent le territoire. Ces musées sont en voie de jouer un rôle plus important que les musées d’État, car ils sont l'expression de la volonté populaire. Ils sont majoritairement fréquentés par les Québécois. La dernière enquête de l'Observatoire de la culture et des communications du Québec montre que ces musées ne s'adressent pas ou que peu aux touristes ${ }^{31}$. Les touristes canadiens, américains et européens recherchent plutôt les grands musées qui présentent l'histoire culturelle du Québec. À l'opposé, les petits musées identitaires s'inscrivent dans l'esprit de la nouvelle muséologie, définie par George Henri Rivière et Hugues de Varine, et se heurtent en quelque sorte à la culture dominante.

On observe une tendance dans les musées d’État au Québec depuis quelques années. Il semble qu'il y est de moins en moins question de culture québécoise. Par moments, il devient politiquement incorrect de parler de «Québécois francophones » que l'on désigne péjorativement par "Québécois de souche ». Certains musées donnent parfois l'impression que l'histoire du Québec commence en 1990 avec le multicuturalisme ou, au mieux, avec la révolution culturelle des années 1960. Bien sûr, cette

31. Yves Bergeron avec la collaboration de Marie-Thérèse Thibault, Le tourisme culturel dans les institutions muséales du Québec, Québec, Observatoire de la culture et des communications du Québec, 2007, 35 p. 
nouvelle vision a des conséquences mesurables. Depuis quelques années, les musées se lancent à la recherche du patrimoine des communautés culturelles. On voit donc apparaître de nouveaux patrimoines en émergence. Les musées redéfinissent un nouveau rapport à l'histoire et au temps qui a notamment pour effet de folkloriser la culture française de même que les cultures minoritaires au Canada. On peut notamment observer ce phénomène dans l'exposition permanente consacrée à l'histoire du Canada au Musée canadien des civilisations. Les Acadiens apparaissent au début du parcours, soit à l'origine de la Nouvelle-France, puis on ne les revoit plus. Les Québécois sont représentés dans la zone réservée à la Place-Royale à la fin du Régime français (1760) et l'histoire se poursuit avec l'Ontario au xix siècle. Les visiteurs passent d'est en ouest du pays en suivant une chronologie qui les conduit $d u x v l^{e}$ au $x x l^{e}$ siècle. On passe donc dans ce long corridor historique de l'ombre à la lumière. L'exposition se termine en apothéose à l'aéroport de Vancouver, qui est devenu un point de chute majeur pour les immigrants. Il est clair que ce concept marginalise la culture francophone, au même titre que la culture des Italo-Canadiens ou des autres communautés culturelles.

\section{Musées et mondialisation de la culture}

Ici comme ailleurs dans le monde, les musées définissent de nouvelles identités régionales et locales. On observe le même phénomène dans plusieurs pays européens, qui prennent conscience que la France, l'Espagne, l'Italie deviennent maintenant des régions de l'Europe. Dans le même esprit, les régions traditionnelles que l'on définissait autrefois comme des pays (la Bretagne, le Limousin, la Provence...) deviennent des sous-régions.

En réaction à ces changements suscités par la mondialisation, on observe qu'il y a valorisation des cultures locales. Ce phénomène est notamment porté par les ministères et organismes qui se consacrent au tourisme. Le tourisme culturel est devenu un des enjeux planétaires de l'économie. Les régions multiplient les inventaires à la recherche des particularismes et des trésors qui permettent de les distinguer. Ce n'est donc pas un effet du hasard si les programmes de formation en patrimoine surgissent à travers le monde et que les musées régionaux se multiplient.

\section{De nouvelles fonctions pour les musées}

Comme nous l'avons montré, les musées nationaux sont au service de l'État et redéfinissent les identités nationales. De même, les musées de communauté (histoire, ethnologie, archéologie) se consacrent à la conservation de la mémoire locale. En ce sens, les musées de société deviennent des marqueurs tangibles des identités locales et régionales. 
Pour marquer le territoire culturel de la francophonie, nous sommes passés de l'église à la croix de chemin, des monuments historiques nationaux au "musée ». Il semble que le musée soit en voie de devenir le monument complet. Il devient le monument qui conserve tout, c'està-dire le patrimoine immobilier, le patrimoine mobilier et le patrimoine immatériel. Il devient lieu de conservation et de fabrication de la mémoire collective. En somme, il résume la nation, la communauté, la famille. En ce sens, le musée reprend son sens premier, c'est-à-dire qu'il est le lieu de conservation de l'héritage de la collectivité, de la famille, c'est-à-dire le bien transmis du père et de la mère aux enfants.

En théorie, le «musée » est aussi le lieu de la mort, c'est-à-dire là où les choses n'ont plus de vie utile, mais où les vestiges des civilisations et du temps passé se retrouvent. N'entrent dans les musées que les objets qui ont perdu leur fonction originale et qui ont acquis de nouvelles fonctions non utilitaires. D’ailleurs, sur les cartels qui décrivent ces objets, on peut lire, comme sur les pierres tombales, le nom de l'objet ou le titre de l'œuvre, l'année de naissance et la date du décès. Au sens propre, le musée est à la fois un conservatoire de la mémoire et un mausolée de la culture.

\section{La réalité des musées au Québec}

Curieusement, on constate que les musées se multiplient en région au moment même où les régions se meurent. Ce n'est pas l'effet du hasard. Certaines régions comme la Gaspésie, la Côte-Nord, l'Abitibi, le SaguenayLac-Saint-Jean ou la Mauricie sont désertées par les jeunes qui choisissent de s'établir dans les deux pôles de la province : Montréal et Québec. Pour compenser cette baisse démographique, les gouvernements créent de nouveaux pôles touristiques et culturels, afin d'attirer de nouveaux publics en saison estivale. C'est pourquoi les musées situés dans les régions ouvrent leurs portes au printemps et ferment l'automne.

Une autre chose est certaine : les Québécois n'occupent plus le territoire. On a parfois l'impression que, dans quelques années, il ne restera dans certaines régions du Québec que des musées comme autant de villages fantômes comme Val-Jalbert au Lac-Saint-Jean, Forillon en Gaspésie ou encore la Grosse-Île près de Québec.

\section{Une crise identitaire}

Quand on examine les changements survenus au cours des dernières années dans les musées, on constate que la mondialisation a eu pour effet de faire éclater la notion de patrimoine. Le rapport Arpin sur le patrimoine publié en 2000 montrait que chaque génération redéfinit son rapport 
au patrimoine ${ }^{32}$. Ces différentes conceptions du patrimoine créent une sorte de confusion des genres chez les citoyens. Malgré l'intérêt pour les objets qui témoignent de l'histoire et de la culture, il semble y avoir une incompréhension face à certains nouveaux objets qui entrent maintenant dans les musées d'histoire. C'est notamment le cas de l'art contemporain et des objets contemporains. Pensons simplement à tous ces objets de la vie quotidienne qui sont rapidement remplacés par de nouvelles technologies et qui trouvent une place dans les réserves des musées (téléphones, ordinateurs, baladeurs, etc.).

Il ne fait aucun doute que la vague de patrimonialisation de la culture pose la question de l'identité collective. C'est ce qui explique notamment que l'ethnologie et la sociologie de la culture retrouvent leur place dans les musées.

Dans Musées et muséologie, nouvelles frontières, nous abordions les tendances sociétales qui transformaient les musées. Nous en arrivions à la conclusion que les véritables frontières ne sont plus territoriales, mais plutôt culturelles. Ce qui distingue encore une fois une culture est invisible au regard et se traduit notamment à travers la langue et le patrimoine immatériel. Il semble que les musées soient en voie de devenir les nouveaux marqueurs territoriaux de la culture. Si tel est le cas, il apparaît de plus en plus évident que le Québec est en voie de devenir une nouvelle marge. Pour mesurer ces changements, il suffit de voir comment se déploient les musées identitaires sur le territoire pour en mesurer les nouvelles frontières.

32. Roland Arpin (prés.), Notre patrimoine, un présent du passé, [Québec, Gouvernement du Québec], Le Groupe-conseil sur la Politique du patrimoine du Québec, novembre 2000, xxx-240 p. 